\title{
Osservazioni dell' Eclisse Solare del 16. Maggio 1882 eseguite al R. Osservatorio
} di Palermo.

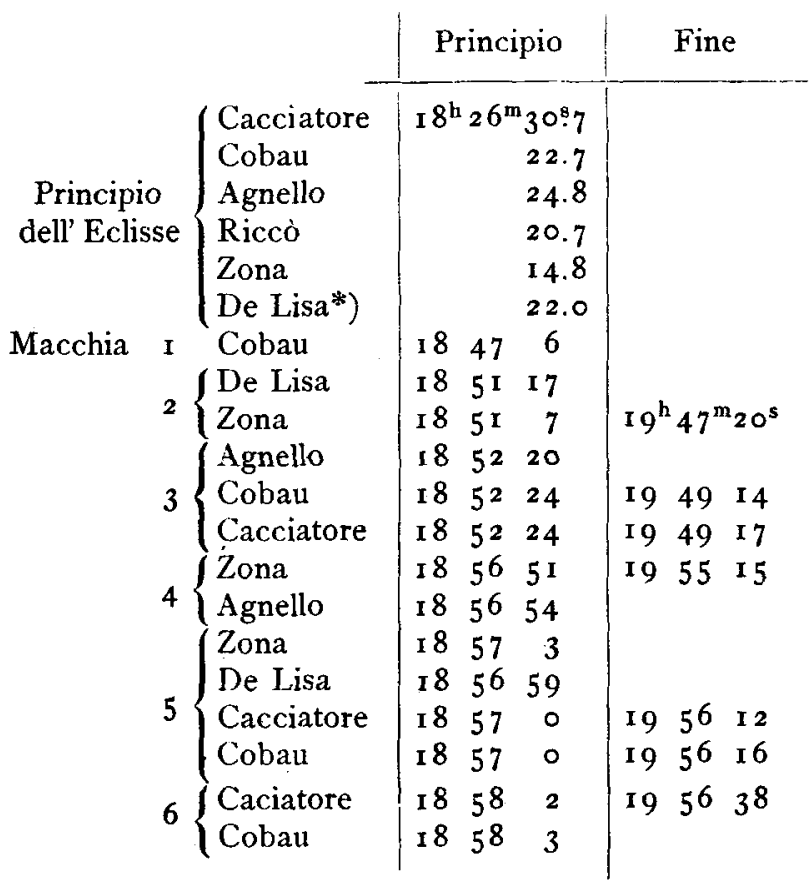

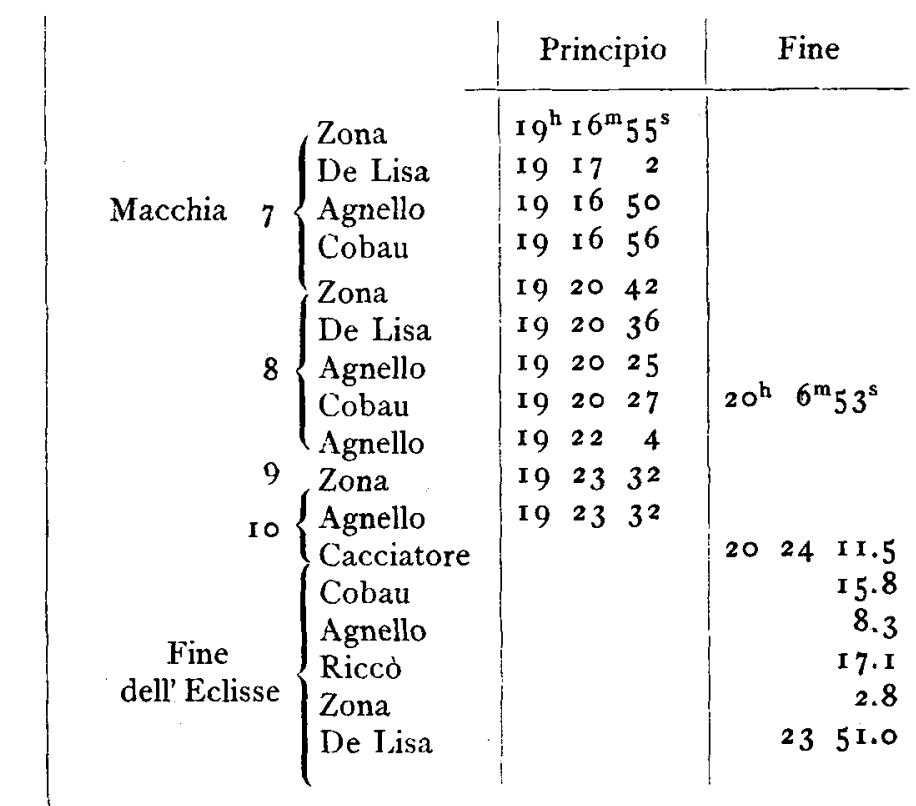

Il Direttore G. Cacciatore.

Kreismicrometer-Beobachtung des Cometen 1881VIII.

\begin{tabular}{|c|c|c|c|c|c|c|c|c|c|}
\hline I 88 I & M. Z. Bothk. & $\Delta a$ & $\Delta \delta$ & Vgl. & $\alpha$ app. & $\log p .4$ & $\delta$ app. & $\log p .4$ & * \\
\hline Dec. ro & $7^{\mathrm{h}} 19^{\mathrm{m}} 56^{\mathrm{s}}$ & $-0^{m} 3^{6^{s}} \cdot 35$ & $+3^{\prime} \mathbf{4}^{2 \prime \prime} \cdot \mathrm{I}$ & 7 & $23^{\mathrm{h}} 43^{\mathrm{m}} 57^{\mathrm{s}} \cdot 43$ & 9.046 & $+42^{c} 55^{\prime} \quad 3^{\prime \prime} 8$ & 0.255 & $x$ \\
\hline
\end{tabular}

Angenommener mittlerer Ort des Vergleichsterns.

\begin{tabular}{|c|c|c|c|}
\hline Stern & $\alpha 1881.0$ & $\delta 1881.0$ & Autorität \\
\hline $\mathbf{I}$ & $\mid 23^{\mathrm{h}} 44^{\mathrm{m}} 29^{\mathrm{s}} \cdot 59+4^{\mathrm{s}} \cdot 19$ & $+42^{\circ} 50^{\circ} 4 I^{\prime \prime} \cdot 3+40^{\prime \prime} 3$ & $W_{2} 23^{h} 916$ \\
\hline
\end{tabular}

Die Beobachtungen geschahen nur am inneren Rande des Ringes, die Declination halte ich für unsicher. Die von Herrn Director J. Schmidt für Dec. ro angegebene Position ist fehlerhaft.*)
Bothkamp 1882 Sept. 27.
L. de Ball.

* Es scheint mir, dass in der Beobachtung Dec. Jo, Nr. 2437 pag. $205, \Delta 8$ mit positiven Zeichen zu nehmen ist, alsdann stimmt die Athener Beobachtung mit der vorstehenden; ebenso auch in Nr. 2416 pag. 253, wo diese Beobachtungen bereits abgedruckt waren, $K r$. 